\title{
The Impact of "Internet Plus" Era on Physical Education in Colleges and Universities and Its Countermeasures
}

\author{
Dingcheng Wang ${ }^{1, \mathrm{a}}$, Bing Shi ${ }^{1, \mathrm{~b}}$, YuLiang Sun ${ }^{1, \mathrm{c}}$ \\ ${ }^{1}$ School of Physical Education, Shaanxi Normal University, Xian 710119, Shaanxi China; \\ a1462543138@qq.com, b378833269@qq.com, 'c1010720@qq.com
}

Keywords: Internet plus, college physical education, internet thinking.

\begin{abstract}
Faced with the craze of the Internet age, college physical education cannot be avoided. This research mainly uses the literature material method, system analysis method, this research mainly studies the physical education in colleges and universities in the age of "Internet + " through literature and data analysis and systematic analysis. The study found that physical education teaching environment, teaching mode, learning methods and other aspects have been seriously affected. We should change the traditional teaching thinking, innovative teaching mode, update teaching methods, MOOC, Micro-lecture, Inverted Classroom and other online classroom into physical education. Students as the main body, pay attention to student learning attitude, self-learning ability training, and students to explore and exchange, give full play to students' initiative. The final "teaching" and "learning" equal "traditional sports classroom + online classroom" teaching mode.
\end{abstract}

\section{Introduction}

Today "Internet plus" has risen to a national strategy. In its Guiding Opinion on Actively Promoting the Internet Plus Plan of Action issued by the State Council in July 2015, the guidelines pointed out that the integration and development of the Internet and various fields have broad prospects and boundless potential and have become an irresistible trend of the times. Social development has a strategic and global impact [1]. This means that we will enter the era of comprehensive information, the Internet will be deeply integrated into all areas of society, the advent of the "Internet plus" era will lead to an educational information revolution in education [2]. The introduction of "Healthy China" and other related policies shows that the state places more emphasis on sports and fully demonstrates the value of sports. "Internet plus" will change all aspects of education in traditional sports. We should adapt to change with a positive attitude and seek innovation.

\section{The Impact of "Internet +" Times on College Physical Education}

\subsection{The impact on the education ecological environment}

The influence of "Internet plus" on advanced education is equivalent to a profound educational reform. It expands the concept of education and teaching space and builds a broader educational space platform [3]. The traditional model of physical education can no longer meet the needs of the current era development and demand.

"Internet plus" has broken the traditional school education model. The successful experience of online courses such as MOOC and Khan Academy has proved that online virtual education can also provide excellent educational services [2]. Education ecological environment is no longer limited to schools and classes, and forms a new and open learning environment that integrates both internal and external integration. The change of traditional teaching environment, diversification of teaching methods and optimization and improvement of teaching efficiency are the important ways for education to adapt to social change.

\subsection{Impact on teachers}

Traditional physical education is the teacher face-to-face demonstration, student imitation practice, the teacher instructed error correction, teachers and students to discuss and exchange students to 
master the sports technology as the main goal, teaching method is to ensure the basic knowledge, the basic skills taught mainly Teacher-based teaching model, shown in Figure 1. This teaching method ignores the students as the main object, the individual differences between students, teacher-student interaction, the cultivation of students' innovation and so on. Teachers are falling behind in thinking, teaching methodically conservative, and have less innovative.

The era of "Internet plus" has a great impact on teachers, and teachers 'authority is challenged while alleviating teachers' teaching pressure and improving teaching efficiency. students are more willing to believe the star player's technical action. By watching the game live, video, learn the star's technical action, usually we take star's technical action as a standard action, scientific research take star as a research object for technical analysis of this phenomenon, which become a serious impact on the teacher's authority. Students are free and scattered, uneven learning activities, practice is not positive, always feel that you can learn to loose phenomenon, but also the impact of the authority of teachers.

The Internet and traditional teaching methods continue to be integrated, through online courses, video materials and other means to actively explore and exchange with students. "Internet plus Education" will inevitably lead to relevant changes in teacher education. How to recognize its position in this rapidly developing world will determine the future of teachers and the quality of education and teaching [4].

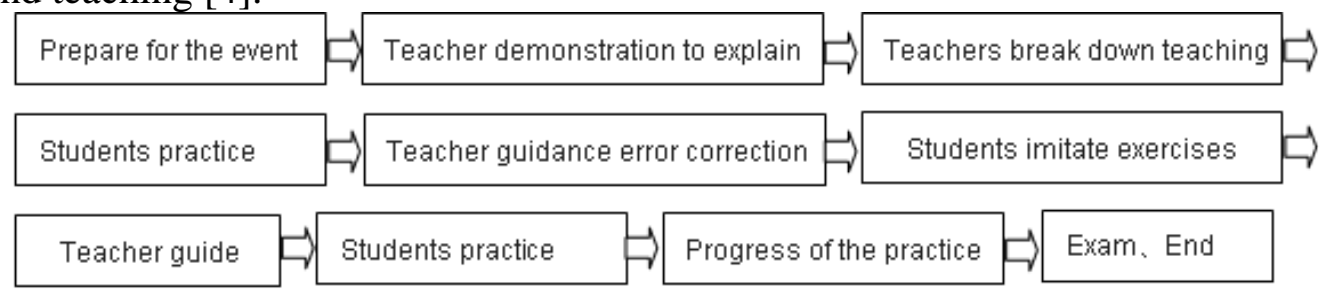

Fig. 1 Traditional sports teaching mode

\subsection{Impact on students}

Learning patterns refers to the students' behavior of participation, cognitive participation and emotional participation in the organic combination of ways in teaching activities. Students growing up in the Internet context, their thinking and acquiring of knowledge and skills are different from those in past ages. The Internet has become a most important way to acquire knowledge beyond the classroom and even surpasses classroom teachers in imparting knowledge, MOOC, Micro-lecture, Inverted Classroom has become their commonly used method of learning [4].

The traditional learning method is based on the class teaching system in the era of machine production. The deep integration of Internet and education has made "Internet plus" education a new normal in education development at this stage. "Internet plus" era students are the discoverer of knowledge, not a simple knowledge of the recipient. Students are no longer confined to the traditional classroom education for acquiring knowledge of sports skills. Students learn through web-based learning websites, e-books and other major learning websites. They extend the knowledge in traditional classrooms to extra-curricular activities and gain international recognition. The popularization of international competitions and promotion of celebrities made most students tend to imitate celebrities more when they learn skills. Students 'suspicion of knowledge conferred on teachers' classrooms let them trust the internet more. Internet brings about changes in learning styles, but also brings students a superficial understanding of sports knowledge. How students choose the correct sports knowledge in the Internet is an urgent problem to be solved in "Internet plus Education".

\section{The Countermeasures of College Physical Education in "Internet +" Era}

\subsection{The Change of Teaching Thinking - Internet Thinking}

Internet thinking refers to the way of thinking in the Internet era - thinking of no distance and networking, that is, a user-centered, people-oriented, knowledge-sharing and exchange-oriented, decentralized way of thinking [5]. 
The impact of "Internet plus" on college physical education is not only the traditional teaching and learning, but also the impact on the traditional thinking of physical education. This is the urgent need of physical education in colleges and universities in the "Internet plus" era. Internet thinking changes the teacher's "teaching" and students "learning." The concept of teaching design is changed to be student-centered, with abundant and diversified teaching content. The main channels of teaching are traditional sports classroom teaching, supplemented by the online classroom. The teaching guidance is based on the interaction of the classroom with the offline education. Students' major changes have been made in their learning styles and self-learning abilities. Their ability to discover knowledge, build their own knowledge framework, learn from each other, search for information, and form their own knowledge system independently has been enhanced.

"Internet thinking" has become one of the main ways of thinking in various fields. It has changed the teaching mode of physical education, communication channels, learning methods, teaching evaluation system, promote teaching reform and innovation and formed a new teaching mode, as shown in Figure 2.

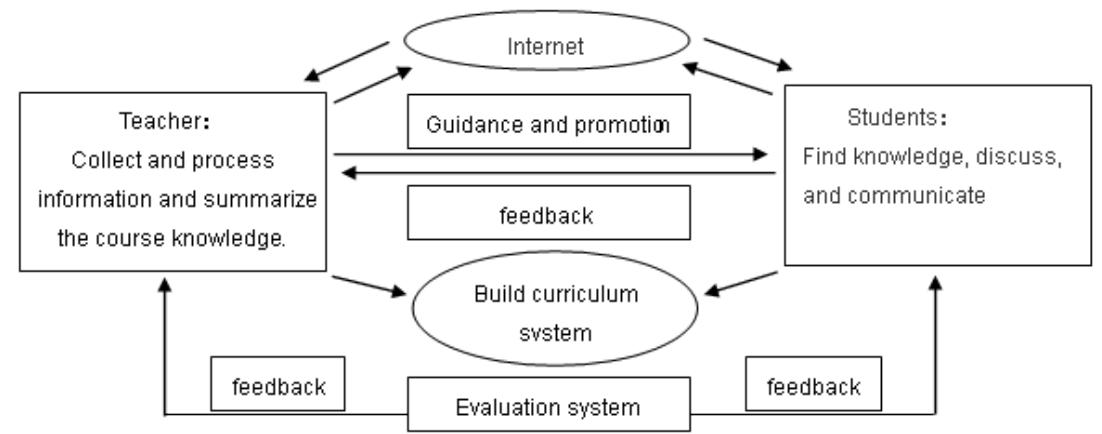

Fig .2 The mode of physical education in the Internet age

\subsection{Coping with "teaching" and "learning"}

Strengthen teachers' knowledge and skills training. In the teaching process, compared with the imparting of knowledge, the cultivation of learning attitude is more important for the development of students. Through the continuous education and training of physical education, teachers can use effective ways to improving students' learning attitude and guide them how to develop more active and health.

Enrich teaching tools. In the process of teaching physical education, teachers can demonstrate technical actions through multimedia means, watch and analyze technical movements with students, arrange teaching tasks, evaluate after class and break the limitation of time and space. Students can learn anytime and anywhere to enhance teaching effectiveness, stimulate students' interest in learning.

Expand teaching methods. Under the guidance of the original syllabus and teaching plan, teachers should actively expand their teaching methods and fully integrate Internet technology into classroom teaching.

Strengthen students' practical awareness. Through repetitive exercises, students should be able to appreciate the difficulty of exercises and then through continuous guidance to enable students to become proficient in technical actions. And then through the network means to feedback the state of student learning guidance timely, so as to strengthen students 'practical awareness and enhance students' understanding of physical education curriculum.

\section{Summary}

The development of "Internet plus" not only brings impact to the traditional physical education, but more importantly, it is a kind of thinking and opportunity. We should rationally accept and examine the opportunities. The "Internet plus" era has brought opportunities for the development of PE in colleges and universities. The cultivation of internet thinking by teachers and students provides the correct direction for the development of contemporary PE teachers 'teaching and students' learning. Teaching methods, teaching tools Diversified development, improve the efficiency of teaching, 
broaden students' access to knowledge and independent choice of ways. Under the background of the rapid development of "Internet plus", the Internet has given new life to the teaching of physical education, It not only changes the simple teaching methods, but also changes the thinking of teachers and students about physical education. In the era of "Internet plus", college physical education must make a response, innovate the traditional sports teaching mode, and actively promote the integration of online class and traditional physical education class. The development of information technology will be an important future development of physical education.

\section{References}

[1] The state council of the communist party of China. Guiding Opinion on Actively Promoting "Internet Plus" Action Plan. (2015-07-04). Chinese government network. http://www.gov.cn/zhengce/content/2015-07/04/content_10002.htm.

[2] Erdun Xiao. Exploration on the Mixed Learning Mode of University Sports Teaching under the Background of "Internet plus". China Electrochemical Education,2017, (10):123-129.

[3] Congmei Liu, Yunsan Tao. Exploration on the Mixed Learning Mode of University Sports Teaching under the Background of "Internet plus". Journal of Chongqing Technology and Business University (Natural Science Edition),2017,34(01):116-120.

[4] Xinxiao Yang, Dianbing Chen, Honglei Zhao. Teaching and Learning from the Perspective of "Internet plus Education". Teaching and Management, 2017, (18):24-27.

[5] Lu Liu, Xilin Yuan, Li Liu. Analysis of Online Classroom Design Elements under Internet Thinking - A Case Study of "Data Analysis" Course. Library and Information Service, 2015,9 (9): 55-61. 